\title{
Maintaining persistence and adherence with subcutaneous growth-hormone therapy in children: comparing jet-delivery and needle-based devices
}

This article was published in the following Dove Press journal:

Patient Preference and Adherence

17 September 2014

Number of times this article has been viewed

\author{
Helen A Spoudeas' \\ Priti Bajaj ${ }^{2}$ \\ Nathan Sommerford ${ }^{3}$ \\ 'London Centre for Paediatric \\ Endocrinology, University \\ College London, London, ${ }^{2}$ Ferring \\ Pharmaceuticals, London, ${ }^{3}$ Health \\ Informatics Research, Sciensus Ltd, \\ Brighton, UK
}

\begin{abstract}
Purpose: Persistence and adherence with subcutaneous growth hormone (GH; somatropin) therapy in children is widely acknowledged to be suboptimal. This study aimed to investigate how the use of a jet-delivery device, ZomaJet ${ }^{\mathbb{}}$, impacts on medication-taking behaviors compared to needle-based devices.
\end{abstract}

Materials and methods: A retrospective cohort study of children aged $\leq 18$ years was conducted using a UK-based, nationwide database of GH home-delivery schedules. Data were evaluated for the period between January 2010 and December 2012 for 6,061 children receiving either Zomacton ${ }^{\circledR}$ (somatropin) via the ZomaJet jet-delivery device or one of six brands of GH all administered via needle-based devices. Persistence was analyzed for patients with appropriate data, measured as the time interval between first and last home deliveries. An analysis of adherence was conducted only for patients using ZomaJet who had appropriate data, measured by proportion of days covered. Brand switches were identified for all patients.

Results: Persistence with GH therapy was significantly longer in patients using ZomaJet compared to needle-based devices ( 599 days versus 535 days, respectively, $\mathrm{n}=4,093 ; P<0.001$ ); this association was observed in both sexes and across age subgroups ( $\leq 10$ and $11-16$ years). The majority $(58 \%)$ of patients using ZomaJet were classed as adherent $(n=728)$. Only 297 patients $(5 \%)$ switched GH brand $(n=6,061)$, and patients tended to use ZomaJet for longer than other devices before switching.

Conclusion: It appears important that the choice of a jet-delivery device is offered to children prescribed daily GH therapy. These devices may represent a much-needed effective strategy for maintaining persistence with subcutaneous $\mathrm{GH}$ administration in children, potentially offering better clinical outcomes and greater cost-efficiency.

Keywords: growth hormone, jet delivery, persistence, adherence, children

\section{Introduction}

In the UK, recombinant growth hormone ( $\mathrm{GH}$; somatropin) is recommended as a treatment option for children with growth failure associated with a variety of conditions including GH deficiency and Turner syndrome. ${ }^{1}$ Long-term GH therapy can help achieve increments in adult height of $8-11 \mathrm{~cm}$ in children with GH deficiency. ${ }^{1}$ Crucially, GH therapy involves daily subcutaneous injections of GH, which may lead to avoidance of therapy in many patients. ${ }^{2}$ Indeed, a high proportion of children experience needle anxiety or injection pain; ${ }^{3}$ therefore, alternative delivery options would be welcome.
Ferring Pharmaceuticals, Drayton Hall,

Church Road, West Drayton, London

UB7 7PS, UK

Tel +442085804148

Fax +4484493I 0058

Email priti.bajaj@ferring.com 
It is widely acknowledged that many patients with longterm conditions do not take their medicines as prescribed. ${ }^{4}$ For optimal treatment outcomes, long-term persistence and adherence with GH treatment is vital. ${ }^{2}$ Although the effects may not be immediate, missing a large number of GH doses is likely to have a substantial long-term impact, including reduced adult height and cost inefficiencies for the health care system. ${ }^{5-7}$ Various factors may cause patients to miss GH doses, including a lack of understanding of the disease and the importance of regular GH administration, and inadequate contact with health care providers. ${ }^{7,8}$

The UK's National Institute for Health and Care Excellence (NICE) recommends that patients should be given a free choice of GH product on an individual basis. ${ }^{1}$ Factors influencing choice include ease of use and whether a needle is required. ${ }^{9}$ Zomacton ${ }^{\circledR}$ (somatropin; Ferring Pharmaceuticals, London, UK) is the only GH therapy available in the UK that is delivered via a jet-delivery device - ZomaJet ${ }^{\circledR}$ (Ferring Pharmaceuticals).$^{10}$ The ZomaJet device is needle-free, and transjects GH through the skin of the user. ${ }^{11}$ Bioequivalence between jet and needle administration has been demonstrated with similar GH-absorption volumes, ${ }^{12}$ with no significant differences in serum IGF-1 levels. ${ }^{13}$

Patients who receive GH treatment in the UK are offered a home-delivery service option through a number of homecare companies, one of which is called Healthcare at Home (HAH). The HAH service delivers the drug and ancillary items (such as the device and transjection heads), and also provides initial training in administration, as well as ongoing support from a dedicated nursing team.

This study investigated medication persistence, adherence, and switching in children prescribed GH therapy, using observational data from the HAH database of delivery schedules. The main objective was to investigate how the use of a jet-delivery device impacts on these medicationtaking behaviors compared to needle-based devices.

\section{Materials and methods Study design and patients}

This was a retrospective cohort study of patients prescribed once-daily subcutaneous doses of GH, which they received through the HAH service. Patients were either receiving Zomacton via the ZomaJet device (the only device available with Zomacton) or one of six brands of GH delivered via various needle-based devices: Genotropin ${ }^{\circledR}$ (Pfizer, Sandwich, UK), Humatrope ${ }^{\circledR}$ (Eli Lilly, Basingstoke, UK), Norditropin ${ }^{\circledR}$ (Novo Nordisk, Crawley, UK), NutropinAq ${ }^{\circledR}$ (Ipsen, Slough, UK), Omnitrope ${ }^{\circledR}$ (Sandoz, Camberley, UK), and Saizen ${ }^{\circledR}$ (Merck Serono, Feltham, UK).
The impact of a jet-delivery device on medication-taking behavior was evaluated in the context of other GH-delivery devices by assessing persistence and brand switching among patients receiving GH treatment. Persistence is defined as the duration of time from initiation to discontinuation of therapy. ${ }^{14}$ An analysis of adherence was also conducted for the subset of patients using the ZomaJet device. Adherence is defined as the degree or extent of conformity to the recommendations about day-to-day treatment by the provider..$^{14}$ Analyses of the individual GH products that use needle-based devices were not conducted, as the required data was proprietary and thus unavailable for publication. Furthermore, needles are available to patients from sources other than $\mathrm{HAH}$, which meant that adherence to individual needle-based devices could not be accurately analyzed using HAH data alone.

Patients who received deliveries of $\mathrm{GH}$ and/or ancillaries between January 2010 and December 2012 were identified from the HAH database of delivery schedules. Most patients (75\%) received both their GH and ancillary items from $\mathrm{HAH}$; a smaller number of "stores-only" patients $(25 \%)$ received only their ancillary items from HAH and collected their GH from a community pharmacy. In the persistence and adherence analyses, patients were excluded if they had reached their 19th birthday by the date of their first prescription (ie, aged $\leq 18$ years), if they did not have appropriate data for calculating a persistence or adherence value, or if they were listed as current at the end of the study period but had not received medication for the past 6 months, as these records were considered to reflect errors in the database or anomalous dispensing events (Figure 1). Patients were excluded from the switch analysis if they had reached their 19th birthday (ie, aged $\leq 18$ years) by the date of their first prescription (Figure 1).

\section{Study evaluations and measures}

Persistence was quantified for each GH brand by the time interval between a patient's first and last delivery of GH and/or ancillaries within the study period. Adherence was estimated using a validated and extensively studied measure known as proportion of days covered (PDC). ${ }^{15} \mathrm{PDC}$ was calculated as the ratio of the number of days a patient had access to viable ZomaJet heads (quantity of heads delivered $\times$ length of time each head should last) to the number of days they were prescribed GH treatment during the treatment period:

$$
\text { PDC }=\frac{\text { Number of days with access to viable heads }}{\text { Number of days receiving treatment }}
$$

PDC was considered to provide a more conservative estimate of adherence compared to the medication-possession 


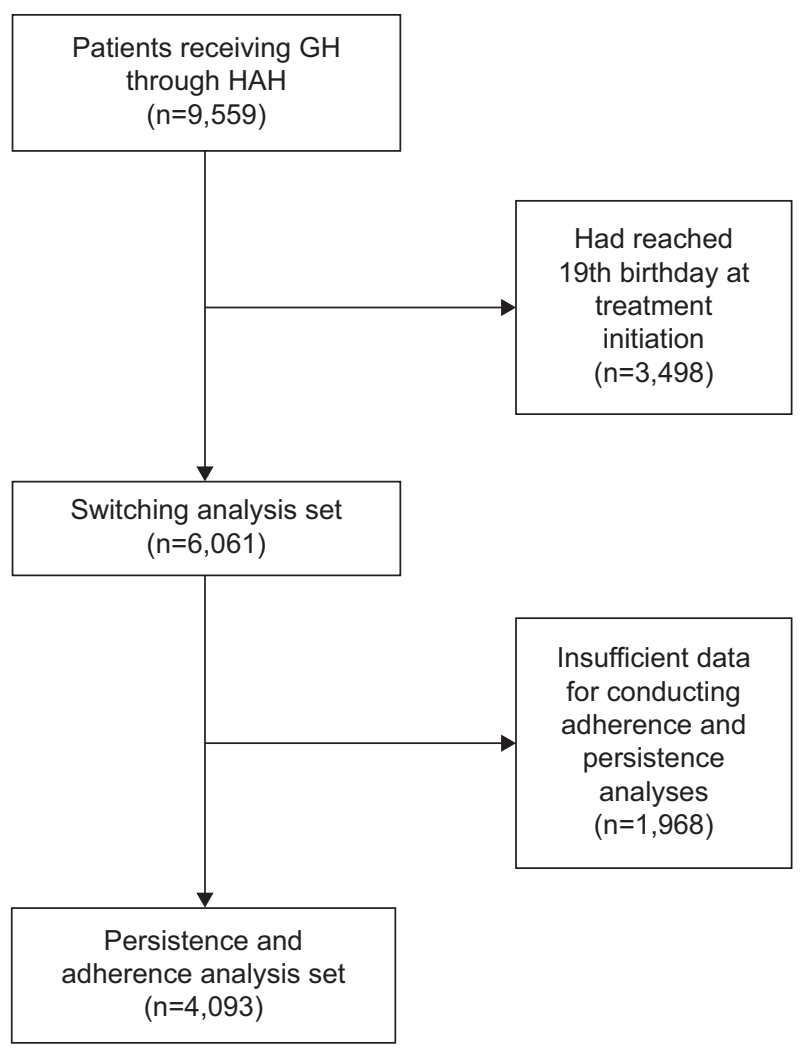

Figure I Patient disposition and analysis sets. Abbreviations: $\mathrm{GH}$, growth hormone; $\mathrm{HAH}$, Healthcare at Home.

ratio (MPR), ${ }^{16}$ and was more robust in this specific context, as it captured patient access to both heads and $\mathrm{GH}$, whereas MPR would only capture one of these two factors. ${ }^{17}$

A PDC score of $>0.8$ suggests that a patient is highly adherent. ${ }^{15}$ A lower score suggests that a patient is using less drug or is reusing heads (contrary to recommendations). Higher scores can occur when prescriptions are refilled before the previous one is exhausted. ${ }^{18}$ Ostensibly, excessive adherence scores typically arise through anomalies in dispensing practice, ${ }^{19}$ eg, a patient may have been oversupplied with heads. Various thresholds and score ranges have been used to classify adherence in previous studies, ${ }^{18,19}$ but no particular range has been validated in this patient population. Therefore, to account for these points, an upper limit was defined within the range of previously used values, and patients with a PDC of $0.8-1.8$ were classed as adherent. Switches between $\mathrm{GH}$ brands were identified on the basis of a change to an alternative brand during the study period.

\section{Statistical analyses}

For comparison of persistence between ZomaJet and needlebased devices, Mantel-Cox log-rank and $\chi^{2}$ tests were used to evaluate statistical significance. Independent-sample $t$-tests were used to evaluate differences in the mean patient age between treatment groups and differences in the percentage of adherent patients between sex and age subgroups. A significance level of $P<0.01$ was used in this study. Persistence was analyzed by linear regression, represented as Kaplan-Meier survival curves, ${ }^{20,21}$ with vertical tick marks denoting when individual patients desisted with treatment. All statistical analyses were undertaken using SPSS (IBM, Armonk, NY, USA).

\section{Results}

\section{Patient disposition and demographics}

A total of 9,559 patient records were extracted from the $\mathrm{HAH}$ database. Of these, 6,061 patients $(63 \%)$ were aged $\leq 18$ years at therapy initiation, of which 4,093 (68\%) provided sufficient data for conducting adherence and persistence analyses (Figure 1). In all, 728 of 4,093 (18\%) were using ZomaJet; the remainder were using needle-based devices. The proportions of males and females in these two treatment groups were similar (Table 1). Patients using needle-based devices were significantly older, at 9.7 years, compared to patients using ZomaJet, at 8.4 years $(P<0.001$, Table 1$)$.

\section{Persistence analysis}

Mean persistence for patients using ZomaJet was significantly longer than for patients using needle-based devices (599 days versus 535 days, respectively; $P<0.001$; Table 2). Survival analyses are shown in Figure 2. Significantly longer persistence with ZomaJet compared to needle-based devices was observed in both males and females (Table 2).

Persistence within the age-groups of $\leq 10$ and 11-16 years was also examined to determine if age influences persistence to GH therapy. Previous studies have suggested that children aged $<10$ years rarely prepare their treatment themselves, ${ }^{11}$ and that $10-11$ years is the age range most commonly suggested by parents for children to begin self-administration. ${ }^{3}$ In addition, Zomacton is licensed for treatment in children up until epiphyseal fusion, ${ }^{22}$ which usually occurs at around 16 years in females and

Table I Patient demographics

\begin{tabular}{|c|c|c|c|}
\hline & $\begin{array}{l}\text { Zomajet } \\
\mathbf{n}=\mathbf{7 2 8}\end{array}$ & $\begin{array}{l}\text { Needle-based } \\
\text { devices } n=3,365\end{array}$ & $\begin{array}{l}\text { Total } \\
n=4,093\end{array}$ \\
\hline \multicolumn{4}{|l|}{ Sex, n (\%) } \\
\hline Female & 304 (4I.9) & I,43I (42.6) & I,735 (42.4) \\
\hline Male & $423(58.1)$ & I,93I (57.4) & $2,354(57.5)$ \\
\hline Not specified & I $(0.1)$ & $3(0.1)$ & $4(0.1)$ \\
\hline \multicolumn{4}{|l|}{ Age, years } \\
\hline Mean (SD) & $8.4(4.0)^{\mathrm{a}}$ & $9.7(4.3)^{\mathrm{a}}$ & $9.5(4.3)$ \\
\hline Range & $1.0-18.6$ & $1.0-18.7$ & $1.0-18.7$ \\
\hline
\end{tabular}

Note: ${ }^{a} p<0.001$.

Abbreviation: SD, standard deviation. 
Table 2 Persistence with growth-hormone therapy

\begin{tabular}{|c|c|c|c|}
\hline & \multicolumn{3}{|c|}{ Persistence in days, mean (SE) } \\
\hline & $\begin{array}{l}\text { Zomajet } \\
n=728\end{array}$ & $\begin{array}{l}\text { Needle-based } \\
\text { devices } n=3,365\end{array}$ & $\begin{array}{l}\text { ZomaJet versus } \\
\text { needle-based devices }\end{array}$ \\
\hline Overall & $599(8.5)$ & $535(3.7)$ & $P<0.001$ \\
\hline \multicolumn{4}{|l|}{ By sex } \\
\hline Female, $\mathrm{n}=1,735$ & $604(13.0)$ & $54 \mid(5.7)$ & $P<0.001$ \\
\hline Male, $n=2,354$ & $596(11.3)$ & $532(5.0)$ & $P<0.001$ \\
\hline Female versus male & $P=0.96$ & $P=0.57$ & \\
\hline \multicolumn{4}{|l|}{ By age } \\
\hline$\leq 10$ years, ${ }^{\mathrm{a}} \mathrm{n}=2,059$ & $617(10.4)$ & $532(5.8)$ & $P<0.000 I$ \\
\hline $1 \mathrm{I}-16$ years, ${ }^{b} \mathrm{n}=1,845$ & $576(14.7)$ & $534(5.1)$ & $P<0.0001$ \\
\hline$\leq 10$ versus $11-16$ years & $P<0.001$ & $P=0.62$ & \\
\hline
\end{tabular}

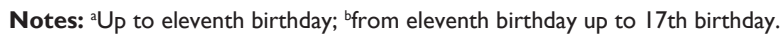
Abbreviation: SE, standard error.

18 years in males. ${ }^{23}$ Therefore, a patient's 17 th birthday was considered an appropriate cutoff age for this analysis. Mean persistence with ZomaJet was significantly longer than with needle-based devices, particularly in patients aged $\leq 10$ years and also in those aged 11-16 years (Table 2). Survival analyses are shown in Figure 3. Among patients using ZomaJet, persistence was significantly longer in those aged $\leq 10$ years compared to $11-16$-year-olds (Table 2). This effect was not observed among patients using needle-based devices (Table 2).

\section{Adherence analysis}

Overall, 424 of 728 patients (58\%) using ZomaJet were classed as adherent (PDC 0.8-1.8, Figure 4A). No correlation was observed between PDC score and service type (full HAH home delivery versus stores only) or dose (data not shown). No significant differences in adherence between

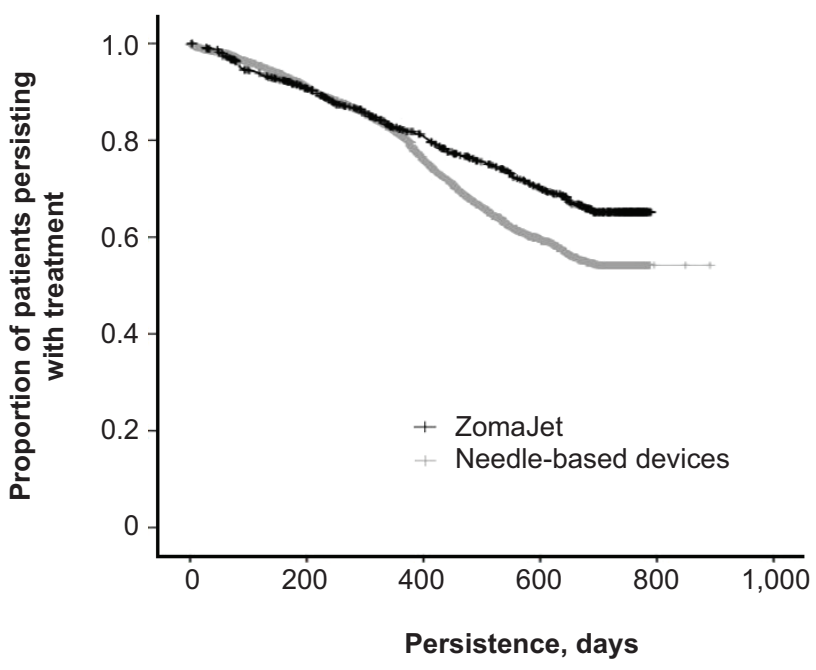

Figure 2 Persistence with growth-hormone treatment in patients using Zomajet or a needle-based delivery device. Vertical tick marks denote when individual patients desisted with treatment. males and females or the two age subgroups were observed (Figure 4B).

\section{Switching analysis}

Of the 6,061 patients eligible for the switch analysis, only 297 (5\%) switched GH brands during the study period. The mean age of patients switching from Zomacton to five of the six alternative brands was equal to or more than the mean age in the reverse switch (Figure 5). In all but one case, patients used Zomacton for longer on average before switching to another brand, compared to the reverse switch (Figure 5).

\section{Discussion}

This study examined medication-taking behaviors in children using the ZomaJet jet-delivery device to administer GH therapy, focusing on persistence and adherence with administration and switching between available products.

The results indicated that patients who chose ZomaJet persisted with treatment for significantly longer compared with those who chose needle-based devices (mean difference 64 days). This could be compared to the findings of an adherence analysis in a previous study in North American children by Desrosiers et al which reported that significantly more patients using a needle-based device had low adherence compared to a jet-delivery device. ${ }^{24}$ It is important to note that children using ZomaJet in the current study were significantly younger than those using needle-based devices, potentially confounding the interpretation of the persistence analysis, as older patients may be more likely to discontinue treatment due to achieving their therapeutic end points (eg, target height gain or epiphyseal fusion). However, subgroup analysis revealed that ZomaJet was associated with improved persistence in both of the age-groups analyzed ( $\leq 10$ years 

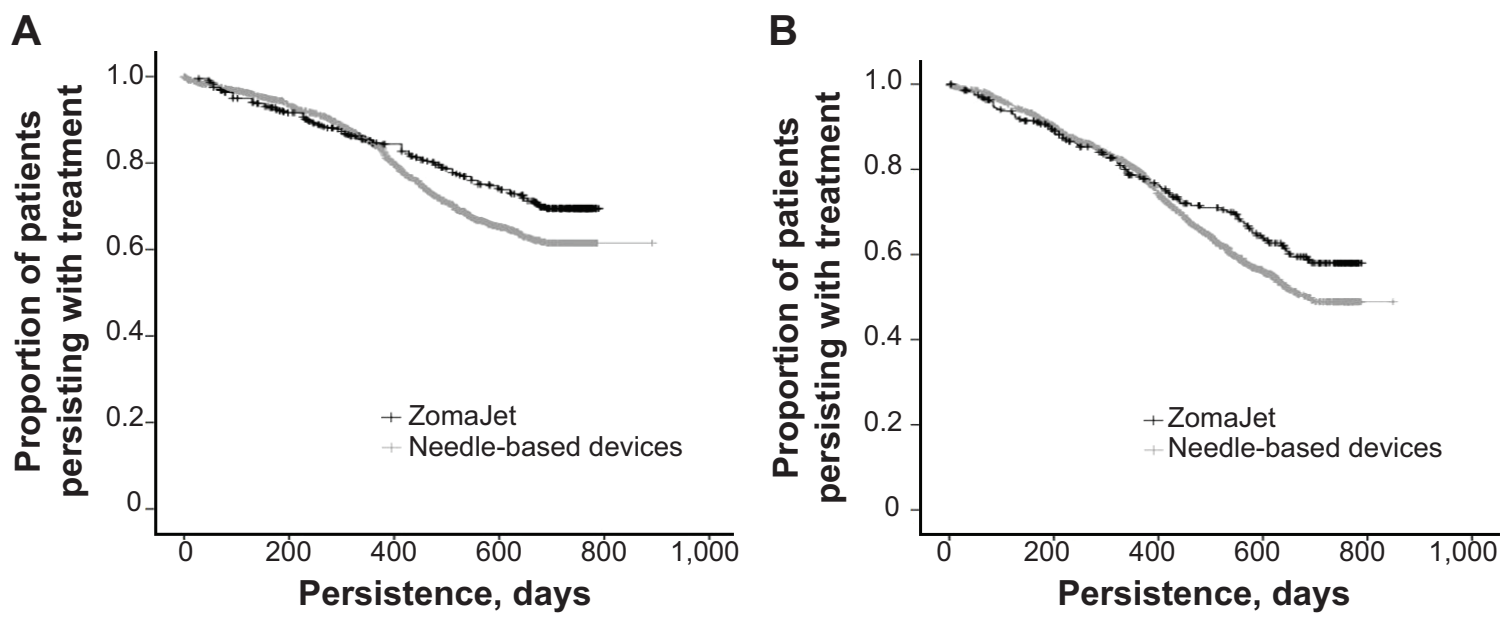

Figure 3 Persistence with growth-hormone treatment in patients using Zomajet or a needle-based delivery device who were $(\mathbf{A})$ aged $\leq 10$ years and $(\mathbf{B})$ aged II-I6 years. Note: Vertical tick marks denote when individual patients desisted with treatment.

and 11-16 years). This supports the interpretation that ZomaJet is associated with improved persistence across age-groups in patients $<17$ years old.

NICE recommends that the choice of a GH delivery device should follow informed discussion between the responsible clinician and the patient/carer, taking into consideration the likelihood of adherence to treatment,

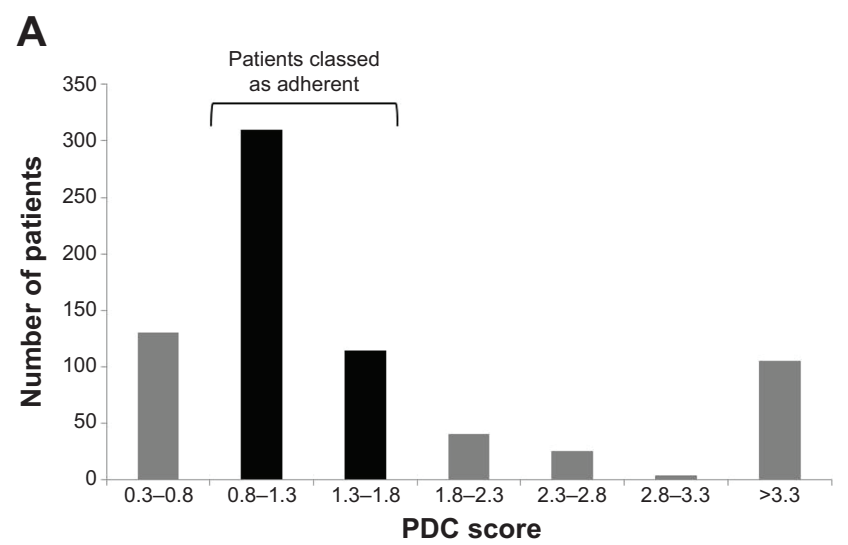

B

\begin{tabular}{|c|c|c|}
\hline & Adherent patients $\mathrm{n}(\%)$ & \\
\hline Overall, $n=728$ & $424(58)$ & \\
\hline \multicolumn{3}{|l|}{ By sex } \\
\hline Female, $n=304$ & $185(61)$ & $P=0.65$ \\
\hline Male, $n=423$ & $238(56)$ & \\
\hline \multicolumn{3}{|l|}{ By age } \\
\hline$\leq 10$ years, ${ }^{a} n=494$ & $287(58)$ & $P=0.18$ \\
\hline $11-16$ years, ${ }^{b} n=234$ & $138(59)$ & \\
\hline
\end{tabular}

Figure 4 Adherence to growth-hormone treatment in patients using Zomajet. Notes: (A) Distribution of adherence scores; (B) subgroup analyses of adherent

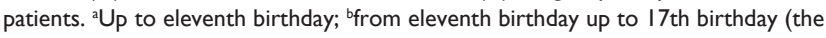
approximate age of epiphyseal fusion).

Abbreviation: PDC, proportion of days covered. among other factors. ${ }^{1}$ In light of these current findings, it may be prudent for clinicians to highlight the growing evidence for an association between jet-delivery devices and improved persistence and adherence when discussing the choice of product with patients. This may be especially relevant in younger patients, who persisted with treatment for significantly longer than older patients when using ZomaJet (but not needle-based devices). When available options are carefully explored, needle-free devices are thought to be a popular choice for GH therapy, eg, $46 \%$ of pediatric patients chose a needle-free device over a needle-based device in a UK hospital clinic. ${ }^{9}$ It is also important to recognize that devices, patient preferences, and published evidence are likely to change over the course of long-term treatment, so device choice should be reviewed regularly. ${ }^{6}$

Although persistence with ZomaJet was significantly longer than with needle-based devices, persistence and adherence in general were markedly suboptimal. Patients persisted with treatment on average for less than 20 months over the course of the 3-year study period (599 and 535 days with ZomaJet and needle-based devices, respectively), and only $58 \%$ of patients were adherent in the ZomaJet-adherence analysis. This raises the specter of suboptimal treatment outcomes and cost inefficiencies, highlighting the need for effective strategies to help patients adhere to their treatment over the long term or identify patients who should discontinue treatment.

While persistence with and adherence to GH therapy have been repeatedly demonstrated to be suboptimal in previous studies, ${ }^{6}$ small sample sizes and substantial differences in patient populations, health care settings, and methodology 


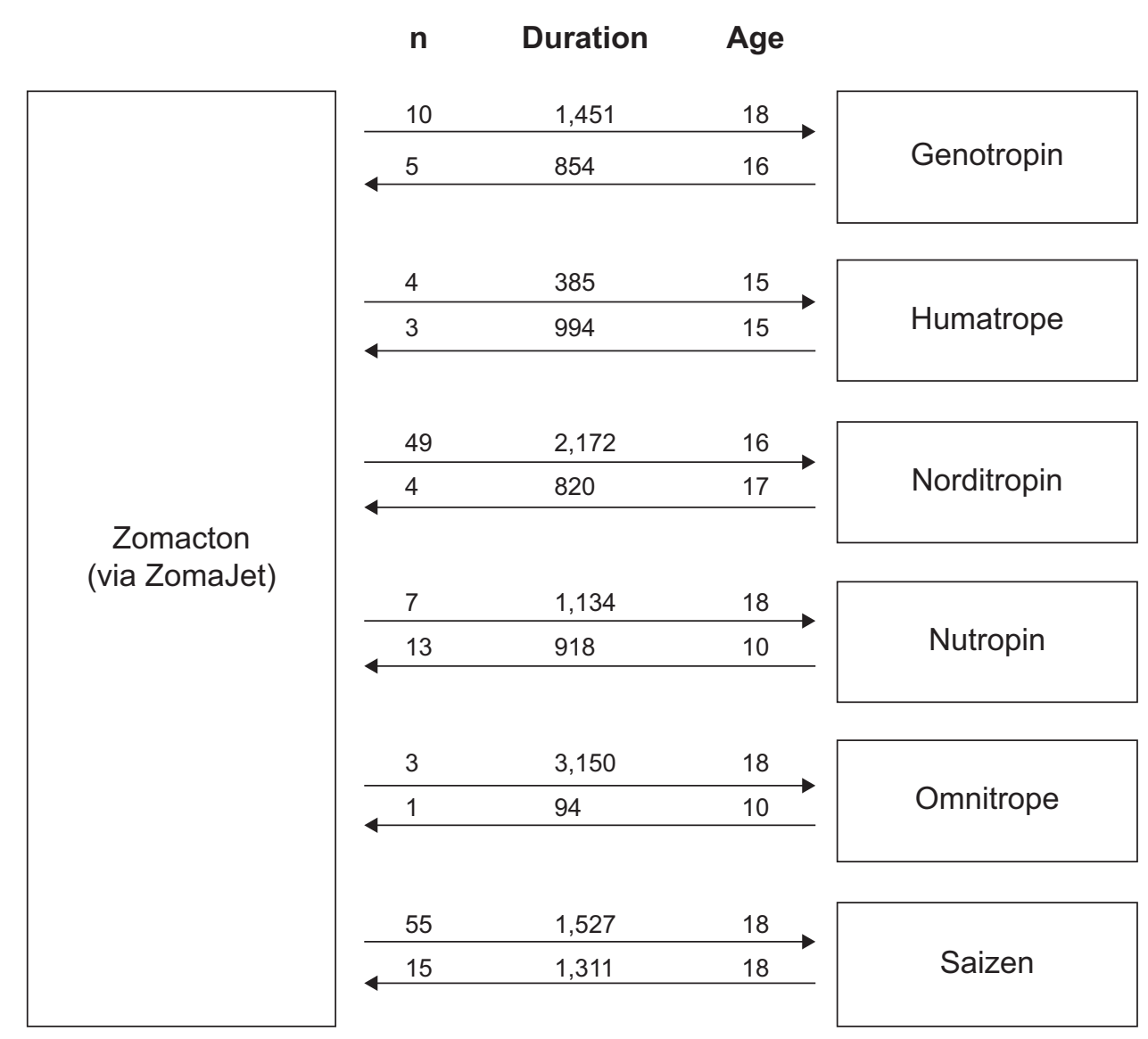

Figure 5 Mean duration that patients used a particular growth hormone brand (days) before switching and mean age at switch (years).

Note: The arrows represent the direction of switch.

mean that estimates vary widely and direct comparisons are difficult. For instance, a recent review found large variations in estimated rates of nonadherence - from 5\% to $82 \%$ - across the literature. ${ }^{6}$ Furthermore, a recent Francebased, prospective study of adherence to ZomaJet found that patients/carers administered $97 \%$ of prescribed GH therapy on average $(n=87)$, suggesting substantially greater adherence than in the current study population..$^{25}$ This suggests that careful consideration of the specific setting is vital when evaluating interventions to improve medication-taking behavior. Results from the current study augment and further clarify our knowledge, being the first UK-based analysis of persistence and adherence to GH therapy in a large cohort of children.

The majority (58\%) of patients using ZomaJet were classed as adherent in the current study, with no difference observed between sexes or age subgroups. While a comparison of adherence with needle-based devices was not undertaken (see Materials and methods), the findings of Desrosiers et al suggest improved adherence with jet-delivery devices in some patients. ${ }^{24}$ Medication adherence is a complex area, affected by several factors that vary between patients and over time. ${ }^{26}$ In GH therapy specifically, lack of choice of delivery device has been identified as a key barrier to adherence. ${ }^{6}$ The choice of device is known to be strongly influenced by its ease of use, ${ }^{6,9}$ and research indicates that many children consider a jet-delivery device easier to use than a needle injection. ${ }^{27}$ This may aid adherence by encouraging self-administration. An additional barrier to adherence that may be addressed through the use of a jet-delivery device is injection discomfort or anxiety. A Dutch study showed that children using a jet device found it less painful and less unpleasant for future use than patients using needle-based devices. ${ }^{27}$ Adherence is also influenced by patient support (including injection training and contact with health care professionals). ${ }^{6}$ The currently available products provide different support services, eg, patients using some GH brands, including ZomaJet, receive injection training and support from nurses for the duration of treatment. By meeting with nurses, a more comprehensive understanding of information from tertiary care specialists can be achieved. ${ }^{3}$ This may also allow carers to feel more involved in treatment decisions, ${ }^{3}$ which may aid adherence. 
In all, $5 \%$ of children switched GH brands during the 3-year study period. Extrapolated over the course of longterm treatment, this could potentially represent a substantial proportion of patients. Patients in the current study generally showed a lengthy persistence with Zomacton before switching: in five out of six cases, patients spent a mean of $>1,000$ days using Zomacton before switching to an alternative product. Although not recorded by HAH, it is likely that switches occur for a variety of reasons. For instance, patient preferences for delivery device may change with age and time. ${ }^{6}$ It should also be noted that the licensed indications differ between brands; in particular, Zomacton is licensed for use in children only up until epiphyseal fusion, ${ }^{22}$ therefore, patients may be moved to another product thereafter. This is suggested by the large numbers of patients switching from Zomacton to Norditropin $(n=49)$ or Saizen $(n=55)$ at the age of 16 or 18 years, respectively (Figure 5). Another reason for switching may be related to costs. The NICE guidelines specify that if no single product is preferred by the patient, the least costly should be chosen. ${ }^{1}$ Therefore, a patient who has no preferred device may initially be prescribed a lowerpriced brand by default. They may then opt to change device once therapy commences.

It is widely acknowledged that there are substantial economic repercussions when patients do not take their medication as prescribed. Indeed, it is estimated that across the UK, around $£ 100$ million is wasted each year on unused medicines alone. ${ }^{28} \mathrm{GH}$ treatment is expensive: costs are estimated by NICE at $£ 6,000 / \mathrm{cm}$ gained for GH deficiency and up to $£ 17,300 / \mathrm{cm}$ gained for Turner syndrome. ${ }^{1}$ Therefore, medicine wastage through nonadherence and nonpersistence could potentially be very costly, and thereby outweigh the perceived advantage of using a low-cost product. Further costs may be incurred when these behaviors go undetected, as clinicians might employ additional diagnostic procedures and/or increase the dose of GH. ${ }^{7}$ Therefore, strategies to improve persistence and adherence not only result in better treatment outcomes for patients but may also reduce costs by reducing medicine wastage and unnecessary effort by clinicians. ${ }^{7}$ While further investigation of the financial impact is required, the improved persistence and adherence ${ }^{24}$ observed with jet-delivery devices in some children suggest these could potentially reduce health care costs.

The HAH database is a valuable data source, allowing meaningful insight into patient behaviors through evaluations of persistence, adherence, and switching. The principal advantages of a database analysis are its objectivity (not relying on subjective patient responses in a survey, for example), and the broad coverage of the patient population that can be achieved. However, the HAH database does not record complete diagnostic criteria or clinical outcomes, such as adult height attained, nor can it shed light on the origins or motivations underlying the observed medicationtaking behaviors.

Further limitations of the results arise from certain aspects of the available data. A large number of patients were excluded from the persistence and adherence analyses for having insufficient data, which may indicate a high prevalence of missing or incomplete data in the database. While this represents a limitation of the results, it should be noted that the sample size remained high.

The nature of the available data meant PDC was chosen as a proxy for adherence, rather than MPR (see Materials and methods), which may be considered a more widely used and accepted measure. ${ }^{17}$ In the persistence analysis, patient numbers were unequal between treatment groups, due to the inclusion and exclusion criteria of the study and the market landscape of the HAH dataset. This was a retrospective real-world study, and not conducted in a controlled study environment, where treatment group sizes can be predefined. However, utilizing a matched patient-pair analysis of this data set controlling for age, diagnosis, and sex would be an interesting approach for further research, and may strengthen the current results.

In the adherence analysis, a large proportion of patients (24\%) were classed as overadherent (PDC >1.8), a phenomenon that has been reported in other database studies..$^{18,19}$ Overadherence is possibly indicative of anomalies in dispensing practice, advocating a cautious interpretation of the results. Additionally, the adherence analysis was limited to patients using ZomaJet, which severely restricts the interpretation of the results. Exploring adherence and persistence with the various needle-based devices would be a promising avenue for future investigations.

It should be noted that in this study, it was not possible for a patient to use more than one brand at once through the HAH service, as patients are switched between devices rather than being permitted use of multiple devices concurrently. However, this analysis could not account for a patient requesting a different type of GH product from their primary care prescriber, in addition to their normal HAH delivery schedule. Further study would be required to elucidate the clinical consequences of changes in medicine-taking behaviors in GH therapy. It would also be interesting to evaluate the impact of home-delivery and support services compared to collection from a community pharmacy. 


\section{Conclusion}

It has long been recognized that implementing strategies to improve persistence and adherence for parenteral treatment might be of particular clinical benefit to patients undergoing GH therapy. ${ }^{6}$ This is the first large-scale UK-based analysis of persistence, adherence, and switching in children receiving $\mathrm{GH}$ therapy. In addition, it is the first persistence analysis comparing a jet-delivery device with needle-based devices.

Although younger on average, children using the ZomaJet device persisted with GH therapy for significantly longer compared with needle-based devices. As such, a treatment program incorporating a jet-delivery device may represent an effective strategy for maintaining regular long-term subcutaneous administration in selected patients. This could potentially improve treatment outcomes, and reduce costs through medicine wastage and unnecessary effort by clinicians, ${ }^{7}$ and these are promising avenues for future investigation. Switching between different $\mathrm{GH}$ brands was recorded over this short time period, suggesting that preferences may change over time, perhaps due to patient age or differences between licensed indications. Taken together, the results indicate that the choice of a jet-delivery or needle-based device should be carefully explored and reviewed in discussions between the clinician and patient/carer, in accordance with NICE guidelines. ${ }^{1}$

\section{Acknowledgments}

Editorial support was provided by Acumen Healthcare Communications Ltd., funded by Ferring Pharmaceuticals. The authors are grateful to Sue Whitten (Ferring Pharmaceuticals) and Matt Jones (formerly of Sciensus Ltd.) for their assistance with this study and manuscript.

\section{Disclosure}

This study was conducted by Sciensus (Brighton, UK), and initiated and funded by Ferring Pharmaceuticals (London, UK). Editorial support was provided by Acumen Healthcare Communications, funded by Ferring Pharmaceuticals. Helen Spoudeas has accepted fees for lecture invitations and received educational grants from Ferring Pharmaceuticals, Novo Nordisk, Pfizer, and Ipsen. Priti Bajaj is an employee of Ferring Pharmaceuticals. Nathan Sommerford is an employee of Sciensus.

\section{References}

1. National Institute for Health and Care Excellence. Human Growth Hormone (somatropin) for the Treatment of Growth Failure in Children. London: NICE; 2010.

2. Yuen KC, Amin R. Developments in administration of growth hormone treatment: focus on Norditropin ${ }^{\circledR}$ Flexpro ${ }^{\circledR}$. Patient Prefer Adherence. 2011;5:117-124.
3. van Dongen N, Kaptein AA. Parents' views on growth hormone treatment for their children: psychosocial issues. Patient Prefer Adherence. 2012;6:547-553.

4. National Institute for Health and Care Excellence. Medicines Adherence: Involving Patients in Decisions about Prescribed Medicines and Supporting Adherence. London: NICE; 2009.

5. Cutfield W, Lindberg A, Albertsson Wikland K, Chatelain P, Ranke MB, Wilton P. Final height in idiopathic growth hormone deficiency: the KIGS experience. KIGS International Board. Acta Paediatr Suppl. 1999;88(428):72-75.

6. Fisher BG, Acerini CL. Understanding the growth hormone therapy adherence paradigm: a systematic review. Horm Res Paediatr. 2013; 79(4):189-196.

7. Haverkamp F, Johansson L, Dumas H, et al. Observations of nonadherence to recombinant human growth hormone therapy in clinical practice. Clin Ther. 2008;30(2):307-316.

8. Rosenfeld RG, Bakker B. Compliance and persistence in pediatric and adult patients receiving growth hormone therapy. Endocr Pract. 2008;14(2):143-154.

9. Wickramasuriya BP, Casey A, Akhtar S, et al. Factors determining patient choice of device for GH therapy. Horm Res. 2006;65(1): $18-22$.

10. Haymarket Medical Media. MIMS Mag. March-May 2014.

11. Kaptein AA. Transjecting growth hormone: continuous nightmare or controlled nuisance? Evaluation of a new needle-free device. Patient Prefer Adherence. 2013;7:703-708.

12. Verhagen A, Ebels JT, Dogterom AA, Jonkman JH. Pharmacokinetics and pharmacodynamics of a single dose of recombinant human growth hormone after subcutaneous administration by jet-injection: comparison with conventional needle-injection. Eur J Clin Pharmacol. 1995;49(1-2):69-72.

13. Agersø H, Møller-Pedersen J, Cappi S, Thomann P, Jesussek B, Senderovitz T. Pharmacokinetics and pharmacodynamics of a new formulation of recombinant human growth hormone administered by ZomaJet 2 Vision, a new needle-free device, compared to subcutaneous administration using a conventional syringe. J Clin Pharmacol. 2002;42(11):1262-1268.

14. Cramer JA, Roy A, Burrell A, et al. Medication compliance and persistence: terminology and definitions. Value Health. 2008;11(1):44-47.

15. Pharmacy Quality Alliance. Proportion of days covered (PDC) as a preferred method of measuring medication adherence. 2014. Available from: http://pqaalliance.org/resources/adherence.asp. Accessed March 18, 2014.

16. Martin BC, Wiley-Exley EK, Richards S, Domino ME, Carey TS, Sleath BL. Contrasting measures of adherence with simple drug use, medication switching, and therapeutic duplication. Ann Pharmacother. 2009;43(1):36-44.

17. Halpern MT, Khan ZM, Schmier JK, et al. Recommendations for evaluating compliance and persistence with hypertension therapy using retrospective data. Hypertension. 2006;47(6):1039-1048.

18. Yang M, Barner JC, Worchel J. Factors related to antipsychotic oversupply among Central Texas Veterans. Clin Ther. 2007;29(6): 1214-1225.

19. Robinson A, Hankins M, Wiseman G, Jones M. Maintaining stable symptom control in inflammatory bowel disease: a retrospective analysis of adherence, medication switches and the risk of relapse. Aliment Pharmacol Ther. 2013;38(5):531-238.

20. Peterson AM, Nau DP, Cramer JA, Benner J, Gwadry-Sridhar F, Nichol M. A checklist for medication compliance and persistence studies using retrospective databases. Value Health. 2007;10(1):3-12.

21. Kaplan EL, Meier P. Nonparametric Estimation from Incomplete Observations. J Am Stat Assoc. 1958;53(282):457-481.

22. Ferring Pharmaceuticals. Zomacton: $10 \mathrm{mg}$ injection [package insert]. London: Ferring Pharmaceuticals; 2012.

23. Freeman JV, Cole TJ, Chinn S, Jones PR, White EM, Preece MA. Cross sectional stature and weight reference curves for the UK, 1990. Arch Dis Child. 1995;73(1):17-24. 
24. Desrosiers P, O'Brien F, Blethen S. Patient outcomes in the GHMonitor: the effect of delivery device on compliance and growth. Pediatr Endocrinol Rev. 2005;2 Supp1 3:S327-S331.

25. Weill J, Niez P. Adherence to the treatment with Zomajet, a needle-free device transjecting growth hormone: results of French observational survey. Poster presented at: European Society for Paediatric Endocrinology Annual Conference; September 19-22, 2013; Milan, Italy.

26. Horne R, Weinman J, Barber N, Elliot RA, Morgan M. Concordance, Adherence and Compliance in Medicine Taking: A Conceptual Map and Research Priorities. London: National Institute for Health Research Service Delivery and Organisation R\&D; 2006.
27. Verrips GH, Hirasing RA, Fekkes M, Vogels T, Verloove-Vanhorick SP, Delemarre-Van de Waal HA. Psychological responses to the needle-free Medi-Jector or the multidose Disetronic injection pen in human growth hormone therapy. Acta Paediatr. 1998;87(2):154-158.

28. Department of Health. Pharmacy in England: Building on StrengthsDelivering the Future. London: Department of Health; 2008.

\section{Publish your work in this journal}

Patient Preference and Adherence is an international, peer-reviewed, open access journal that focuses on the growing importance of patient preference and adherence throughout the therapeutic continuum. Patient satisfaction, acceptability, quality of life, compliance, persistence and their role in developing new therapeutic modalities and compounds to optimize clinical outcomes for existing disease states are major areas of interest for the journal. This journal has been accepted for indexing on PubMed Central. The manuscript management system is completely online and includes a very quick and fair peer-review system, which is all easy to use. Visit http://www. dovepress.com/testimonials.php to read real quotes from published authors.

\footnotetext{
Submit your manuscript here: http://www.dovepress.com/patient-preference-and-adherence-journal
} 